\title{
Comparative Assessment of the Activity of Decoquinate and Its Quinoline-O-Carbamate Derivatives against Toxoplasma gondii in vitro and in Pregnant Mice Infected with T. gondii Oocysts
} Jessica Ramseier 1,*, Dennis Imhof 1,2, Nicoleta Anghel 1,2, Kai Hänggeli 1,2, Richard M. Beteck ${ }^{3}$, Vreni Balmer 1, LuisMiguel Ortega-Mora ${ }^{4}$, Roberto Sanchez-Sanchez ${ }^{4}$, Ignacio Ferre ${ }^{4}$, Richard K. Haynes ${ }^{3}$, Andrew Hemphill 1,*

1 Institute of Parasitology, University of Bern, Department of Infectious Diseases and Pathobiology, Vetsuisse Faculty, Länggass-Strasse 122, 3012 Bern, Switzerland; jessi95@gawnet.ch; vreni.balmer@vetsuisse.unibe.ch; andrew.hemphill@vetsuisse.unibe.ch

2 Graduate School for Cellular and Biomedical Sciences, University of Bern, Mittelstrasse 43, 3012 Bern, Switzerland; dennis.imhof@vetsuisse.unibe.ch; nicoleta.anghel@vetsuisse.unibe.ch; kai.haenggeli@vetsuisse.unibe.ch

3 Centre of Excellence for Pharmaceutical Sciences, Faculty of Health Sciences, North-West University, Potchefstroom 2520, South Africa; haynes@ust.hk; 25159194@nw.ac.za

4 SALUVET, Animal Health Department, Faculty of Veterinary Sciences, Complutense University of Madrid, Ciudad Universitaria s/n, Madrid, Spain; luis.ortega@ucm.es; robers01@ucm.es; iferrepe@vet.ucm.es

* Correspondence: andrew.hemphill@vetsuisse.unibe.ch (AH); jessi95@gawnet.ch (JR)

\begin{abstract}
The quinolone decoquinate (DCQ) is widely used in veterinary practice for the treatment of bacterial and parasitic infections, most notably coccidiosis in poultry and in ruminants. We have investigated the effects of treatment of Toxoplasma gondii in infected human foreskin fibroblasts (HFF) with DCQ. It induced distinct alterations in the parasite mitochondrion within $24 \mathrm{~h}$, which persisted even after long-term ( $500 \mathrm{nM}, 52$ days) treatment, although there was no parasiticidal effect. Based on the low half-maximal effective concentration (IC $\mathrm{C}_{50}$ ) of $1.1 \mathrm{nM}$ and the high selectivity index of $>5000$, the efficacy of oral treatment of pregnant mice experimentally infected with $T$. gondii oocysts with DCQ at $10 \mathrm{mg} / \mathrm{kg} /$ day for 5 days was assessed. However, the treatment had detrimental effects, induced higher neonatal mortality than $T$. gondii infection alone, and did not prevent vertical transmission. Thus, three quinoline-O-carbamate derivatives of DCQ anticipated to have better physicochemical properties than DCQ were assessed in vitro. One such compound RMB060 displayed an exceedingly low IC 50 of $0.07 \mathrm{nM}$ when applied concomitantly with infection of host cells and had no impact on HFF viability at $10 \mu \mathrm{M}$. As was the case for DCQ, RMB060 treatment resulted in alteration of the mitochondrial matrix and loss of cristae, but the changes became apparent at just $6 \mathrm{~h}$ after commencement of treatment. After 48h, RMB060 induced the expression of the bradyzoite antigen BAG1, but TEM did not reveal any other features reminiscent of bradyzoites. Exposure of infected cultures to $300 \mathrm{nM}$ RMB060 for 52 days did not result in complete killing of all tachyzoites, although mitochondria remained ultrastructurally damaged and there was a slower proliferation rate. Treatment of mice infected with T. gondii oocysts with RMB060 did reduce parasite burden in non-pregnant mice and dams, but vertical transmission to pups could not be prevented.
\end{abstract}

Keywords: quinolone; decoquinate; Toxoplasma gondii; tachyzoites, bradyzoites, oocysts, vertical transmission, proliferation, resistance.

\section{Introduction}


Toxoplasma gondii is one of the most successful parasites on this planet, it infects a wide variety of mammalian species and almost one-third of the human population. Felids are the definitive hosts, whereas virtually all warm-blooded animals, including humans serve as intermediate hosts [1]. The life cycle of the parasite comprises three distinct stages: (i) tachyzoites, which are rapidly proliferating and cause acute disease by undergoing continuous host cell invasion, proliferation and egress (lytic cycle); (ii) bradyzoites, which divide slowly, form tissue cysts and can persist within intermediate hosts for extended periods of time; (ii) sporozoites, encapsulated in sporocysts within sporulated oocysts. Sexual development takes place in the intestinal tissue of felids, resulting in the formation of oocysts, which are shed into the environment. Infection takes place through the oral route, either by ingestion of tissue cysts in raw or undercooked meat or by oocysts present in the environment, and also through vertical transmission of tachyzoites upon primary infection during pregnancy [2]. In ruminants such as sheep and goats and other farm animals, toxoplasmosis often causes abortion, which has serious economic consequences. In humans, most infections are asymptomatic, but toxoplasmosis can inflict serious disease in immunocompromised individuals and newborns. The high zoonotic potential of this disease poses a serious health concern worldwide [3].

The drugs currently used for chemotherapy of human and animal toxoplasmosis are either sulfadiazine or clindamycin, both combined with pyrimethamine, or trimethoprimsulfamethoxazole, with leucovorin added to prevent hematologic toxicity. Atovaquone or azithromycin combined with pyrimethamine or sulfadiazine are alternative treatment options [4]. The macrolide antibiotic spiramycin is prescribed immediately after diagnosis of maternal infection and changed to pyrimethamine-sulfonamide combination when fetal infection is diagnosed or in case where infection is acquired in late pregnancy [5]. However, treatment failures caused by the need to cease treatment due to serious adverse events are frequently observed, and the prolonged courses of therapy required for treatment and suppression of infection are a serious problem. In addition, drug resistance can occur by as yet unspecified pathways [6]. The currently chemotherapeutic treatment regimens affect the acute stage of toxoplasmosis, but will not completely eradicate the infection during active multiplication of the parasite [7], thus leaving an escape route for tachyzoites enabling them to differentiate into bradyzoites, which form long-lived and drug-resistant tissue cysts. There is no Toxoplasma vaccine available for use in humans, but a live-vaccine (Toxovax ${ }^{\mathrm{R}}, \mathrm{MSD}$ Animal Health) that has been on the market for many years, which helps to prevent abortion in sheep flocks [1]. Thus, there is an urgent need for the development of new safe and effective drugs for the treatment of toxoplasmosis. A promising approach for the identification of novel chemotherapeutic options is repurposing of drugs that were originally developed for other indications [8-10].

Decoquinate (DCQ; ethyl 6-decyloxy-7-ethoxy-4-oxo-1H-quinoline-3-carboxylate, Fig. 1A) is a quinolone derivative that has been originally developed for the treatment of coccidiosis in poultry, but is now also commercialized in many countries worldwide for the use in ruminants [11]. DCQ inhibits oxidative phosphorylation and thus the generation of ATP in the mitochondrion by interfering with the electron transfer from ubiquinone to cytochrome $c$, thus acting as a cytochrome $b c 1$ inhibitor [12]. DCQ has a good safety profile, and although it is highly lipophilic and has exceedingly low aqueous solubility $(0.06 \mu \mathrm{g} / \mathrm{ml})$ it is able to be used for treatment of intestinal infections [13]. DCQ has been formulated to treat gastrointestinal coccidiosis in cattle, small ruminants and poultry at concentrations of approximately $0.5 \mathrm{mg} / \mathrm{kg}$ body weight. In milking cows treated with the formulated DCQ, the maximum concentration of DCQ attained in plasma was $2 \mu \mathrm{M}$, a level well above its therapeutic effect [14].

The efficacy of DCQ against T. gondii in vitro has been demonstrated; it inhibits $T$. gondii proliferation in vitro with an $\mathrm{IC}_{50}$ value of $12 \mathrm{nM}$ [15]. DCQ also has prophylactic 
properties. In ewes that were submitted to treatment with DCQ commencing 10 days prior to infection with $T$. gondii oocysts, treatment resulted in decreased pathological changes in the placental tissue, increased viability and weight of newborn lambs, and reduced febrile and humoral immune responses upon infection [16].

In the light of the notoriously poor drug like properties of DCQ, attempts have been made to improve these properties. Thus, highly polar groups have been added to generate DCQ prodrugs with enhanced water solubility [17]. In our case, in order to render DCQ more useful for treating systemic infections, DCQ was converted into the quinoline-Ocarbamate derivatives RMB054, RMB055 and RMB060 (Fig. 1). These quinoline-O-carbamates displayed in vitro efficacies with half maximal effective concentrations (IC 50 values) against $T$. gondii in the low $\mathrm{nM}$ range, and negligible cytotoxicity against human foreskin fibroblasts and human fetal lung fibroblasts [18].

In this study, we demonstrate the efficacies of RMB054, RMB055 and RMB060 in comparison with DCQ in vitro, describe the ultrastructural changes upon drug exposure, and investigate the effects of long-term treatments with DCQ and the derivatives in vitro. In addition, we assessed the efficacy of RMB060 against $T$. gondii oocyst infection in pregnant mice in comparison with DCQ.

\section{Results}

2.1. Efficacy of DCQ against T. gondii in vitro and in $C D 1$ mice infected with $T$. gondii oocysts

The efficacy of DCQ in vitro was determined using T. gondii $\beta$-gal constitutively expressing $\beta$-galactosidase grown in HFF monolayers. When DCQ was added concomitantly with infection, the IC 50 was $1.1 \mathrm{nM}$. As DCQ did not affect HFF viability at $5 \mu \mathrm{M}$, it thus displays a selectivity index of $>5000$. However, the efficacy decreased, as reflected in an increase of the IC 50 to $4.7 \mathrm{nM}$, when the compound was added to cultures already har-

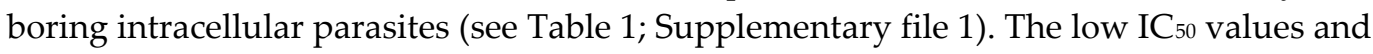
the low degree of cytotoxicity against HFF host cells in vitro encouraged us to examine the efficacy of oral treatment of CD1 mice infected with T. gondii oocysts with DCQ at 10 $\mathrm{mg} / \mathrm{kg} /$ day for 5 days. The results of this experiment are summarized in Table 2.

A

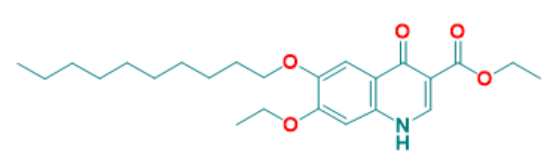

C

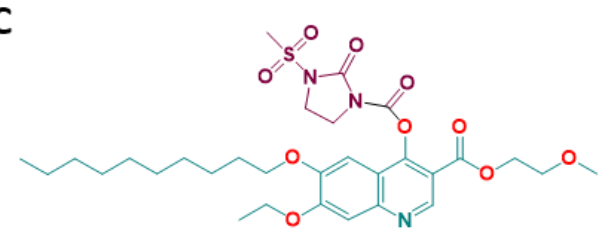

B

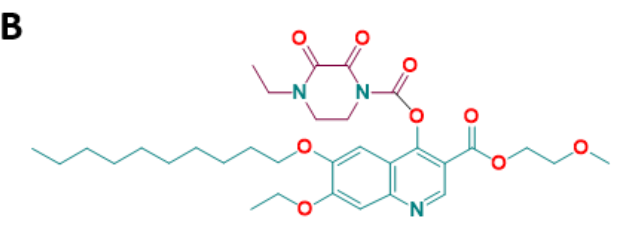

D

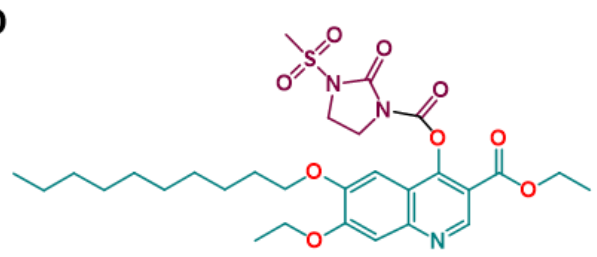

Figure 1. Structures of decoquinate (DCQ) and its quinoline-O-carbamate derivatives. (A) DCQ, $\mathrm{C}_{24} \mathrm{H}_{35} \mathrm{NO}_{5}, \mathrm{MW}=417.546$; (B) RMB054, $\mathrm{C}_{32} \mathrm{H}_{45} \mathrm{~N}_{3} \mathrm{O}_{9}, \mathrm{MW}=615.724$; (C) $\mathrm{RMB}_{1} \mathrm{R}_{5}, \mathrm{C}_{30} \mathrm{H}_{43} \mathrm{~N}_{3} \mathrm{O}_{10 S}$, MW $=637.745 ;$ (D) RMB060, $\mathrm{C}_{29} \mathrm{H}_{41} \mathrm{~N}_{3} \mathrm{O} 9 \mathrm{~S}, \mathrm{MW}=607.719$.

Table 1. In vitro activities against $T$. gondii and cytotoxicity against HFF. 


\begin{tabular}{llll}
\hline Compounds & $\begin{array}{l}\text { IC50 T. gondii (nM) }[\mathrm{LS} ; \mathrm{LI}]^{\mathrm{a}} \\
\text { Compound added prior to infection }\end{array}$ & $\begin{array}{l}\text { IC50 T. gondii }(\mathrm{nM})[\mathrm{LS} ; \mathrm{LI}]^{\mathrm{a}} \\
\text { Compound added 3h post-infection }\end{array}$ & IC50 HFF $(\mu \mathrm{M})$ \\
\hline DCQ & $1.1[3 ; 0.4]$ & $4.7[10.1 ; 2.1]$ & $>5^{\mathrm{b}}$ \\
RMB054 & $11.5[16.6 ; 8]$ & $11.4[15.5 ; 8.5]$ & $>5^{\mathrm{b}}$ \\
RMB055 & $199.6[234.6 ; 169.8]$ & $226.7[240.9 ; 213.4]$ & $>10^{\mathrm{b}}$ \\
RMB060 & $0.07[0.14 ; 0.03]$ & $0.7[1.22 ; 0.4]$ & $>10^{\mathrm{b}}$ \\
\hline
\end{tabular}

aValues at 95\% confidence interval (CI); LS (limit superior) and LI (limit inferior) are the upper and lower limits of the CI, respectively. ${ }^{b}$ Values cannot be calculated as there is no decline in viability over the concentration range.

One dam of the DCQ group showed clinical signs of oocyst infection, including ruffled coat, weak appearance and respiratory problems, and had to be euthanized one day after she gave birth. All pups were born dead, and during necropsy, 4 more pups were found. Furthermore, two dams from the DCQ and one from the C+ group gave birth to non-viable pups. Overall, DCQ treatment led to increased neonatal pup mortality of $70 \%$ (64 out of 92 pups) compared to $40 \%$ (37 out of 92 pups) in the non-treated but infected $\mathrm{C}+$ group (Fig. 2A). In addition, 3 of the 28 remaining pups from the DCQ group died during the first 16 days of the 1-month follow-up phase, while no postnatal mortality was observed in the $\mathrm{C}+$ group (Table 2). Of the 25 surviving pups in the DCQ group, all were tested PCR-positive for T. gondii in the brain, and in the C+ group 35 of the 55 surviving pups $(64 \%)$ were tested PCR-positive. In the adult mice, including dams and non-pregnant mice, of the DCQ and the C+ group, brain infection was detected in 11 out of 12 mice (Table 2). No difference in parasite load between the DCQ and the C+ group could be observed, and the mean values were even slightly higher in the DCQ group (Fig. 2B and C). In all $T$. gondii brain positive mice, increased IgG serum-levels were recorded, and IgG titers of the DCQ and the C+ group were in the same range (Supplementary file 2). Thus, despite highly promising IC 50 values and the low cytotoxicity seen in vitro, DCQ treatment did not protect adult mice from $T$. gondii infection and had a detrimental impact on pup survival by causing more neonatal mortalities than those infected with $T$. gondii alone.

Table 2. Litter size, parasite burden, neonatal and postnatal mortality rates of T. gondii infected mice treated with DCQ.

\begin{tabular}{|c|c|c|c|c|c|c|c|c|}
\hline Treatment & Challenge & $\begin{array}{l}\text { Seropositive } \\
\text { for } T \text {. gondii }\end{array}$ & $\begin{array}{l}\text { T. gondii positive } \\
\text { non-pregnant mice }\end{array}$ & $\begin{array}{l}\text { T. gondii posi- } \\
\text { tive dams }\end{array}$ & $\begin{array}{l}\text { No. of pups/ } \\
\text { no of dams }\end{array}$ & $\begin{array}{l}\text { Neonatal } \\
\text { mortality }\end{array}$ & $\begin{array}{l}\text { Postnatal } \\
\text { mortality }\end{array}$ & $\begin{array}{l}\text { T. gondii posi- } \\
\text { tive pups }\end{array}$ \\
\hline $10 \mathrm{mg} / \mathrm{kg}$ & TgShSp1 & $11 / 12$ & $3 / 4$ & $8 / 8$ & $92 / 8$ & $64 / 92$ & $3 / 28$ & $25 / 25$ \\
\hline DCQ & oocysts & & & & & & & \\
\hline Corn oil & $\begin{array}{l}\text { TgShSp1 } \\
\text { oocysts }\end{array}$ & $9 / 12$ & $4 / 4$ & $7 / 8$ & $92 / 8$ & $37 / 92$ & $0 / 55$ & $35 / 55$ \\
\hline Corn oil & PBS & $0 / 5$ & $0 / 2$ & $0 / 3$ & $41 / 3$ & $0 / 41$ & $0 / 41$ & $0 / 41$ \\
\hline
\end{tabular}


A

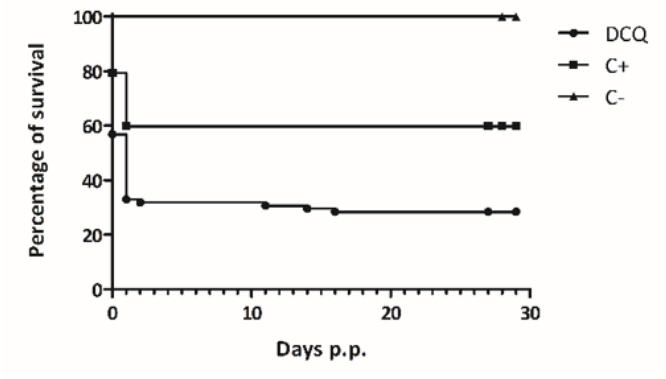

B

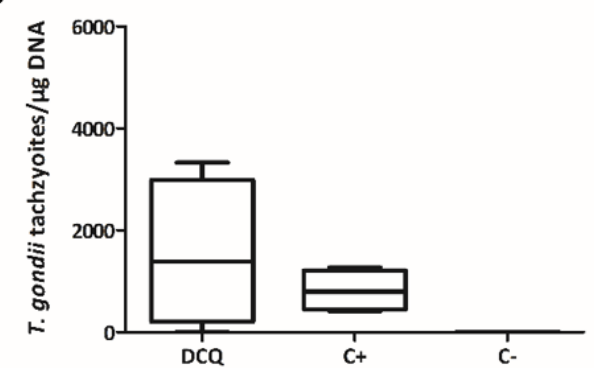

C

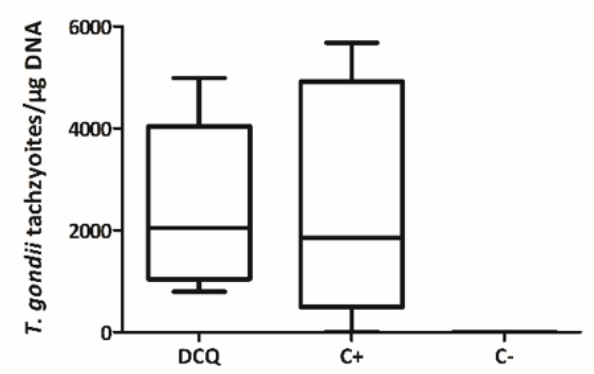

Figure 2. DCQ treatment in the pregnant toxoplasmosis mouse model. Survival curves of pups (A) and cerebral parasite burden of non-pregnant mice (B) and dams (C). Survival rates were plotted in Kaplan-Meier graphs at each time point and curves were compared by the Log-rank (Mantel-Cox) test. Differences between the three curves were highly significant $(P<0.0001)$. CD1 mice were infected with $50 \mathrm{TgShSp} 1$ oocysts and treated with $10 \mathrm{mg} / \mathrm{kg}$ DCQ, while C+ was infected and treated only with corn oil. C- was not infected and treated with corn oil alone. 4 weeks p.p. all mice were euthanized, brains were aseptically collected, and cerebral parasite burden was quantified by realtime PCR. The values are depicted as box plots and parasite burden between groups were compared by the Kruskal-Wallis test, followed by the Mann-Whitney-U test. No statistically significant differences in the cerebral parasite burden were observed between DCQ-treated mice compared to the C+ group (neither in non-pregnant mice nor in dams).

\subsection{Efficacies of the quinoline-O-carbamate derivatives of DCQ in vitro}

Due to the negative effects of treatment with DCQ, we investigated the efficacy in vitro of the three DCQ derivatives RMB054, RMB055 and RMB060 (Fig. 1) [18] in comparison to DCQ. Different concentrations of DCQ and the derivatives in DMSO were added to HFF either concomitantly with infection of $T$. gondii- $\beta$-gal tachyzoites, or $3 \mathrm{~h}$ after infection. In the former case, IC50 values were $11.5 \mathrm{nM}$ for RMB054, $199.6 \mathrm{nM}$ for RMB055, and $0.07 \mathrm{nM}$ for RMB060. When compounds were added after infection, the IC 50 values for RMB054 and RMB055 remained in a similar range, while it was tenfold inferior for RMB060, indicating that the last compound not only had an impact on intracellular proliferation but also exerted pronounced activity on extracellular tachyzoites and inhibited host cell invasion. The corresponding dose-response curves are shown in Supplementary file 1 . The viability of uninfected HFF was not impaired by the compounds up to concentrations of $5 \mu \mathrm{M}$ (DCQ and RMB054) or $10 \mu \mathrm{M}$ (RMB055, RMB060) (Table 1). 

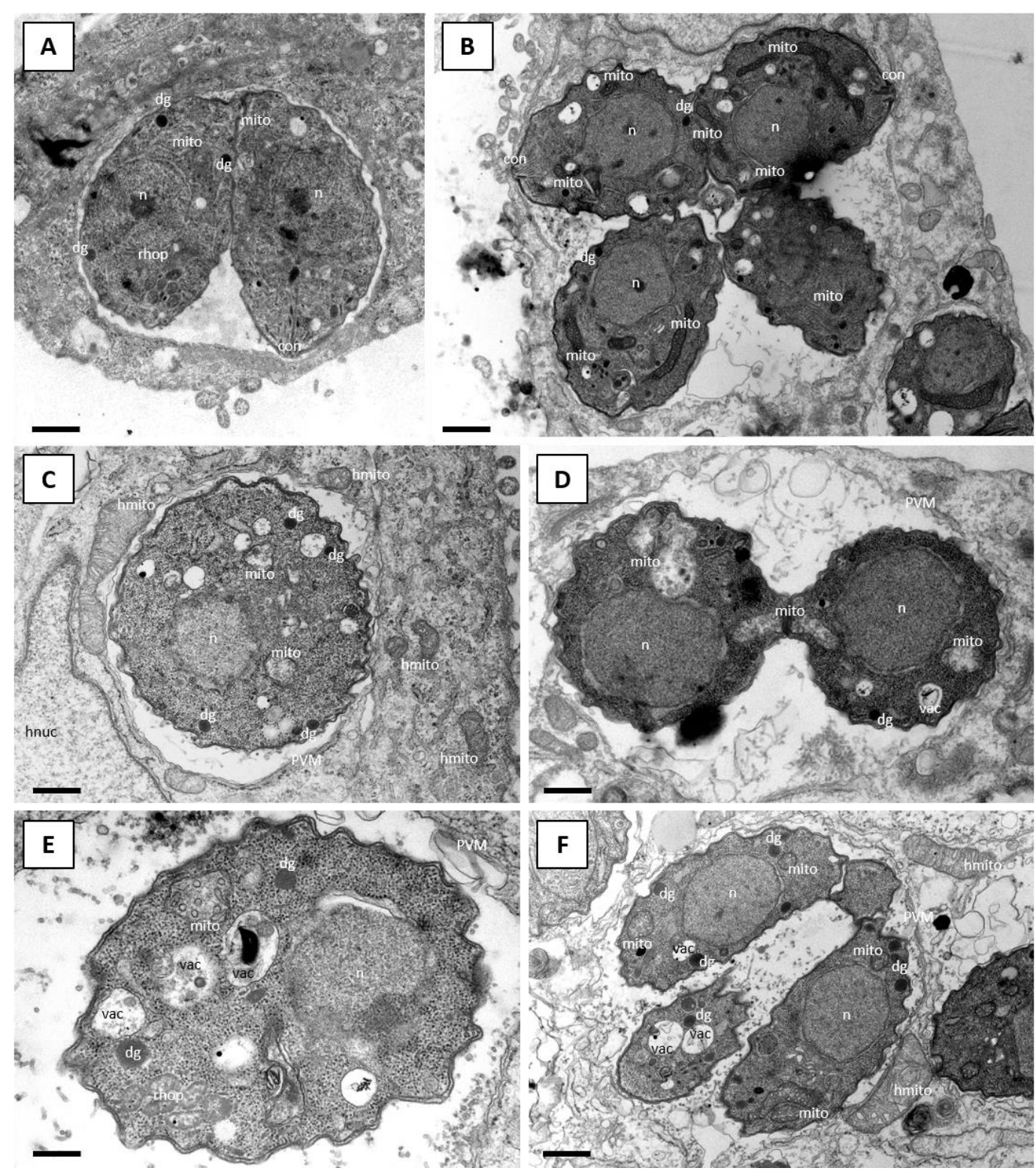

Figure 3. TEM of T. gondii Me49 tachyzoites cultured in vitro in HFF host cells. HFF monolayers were infected with $T$. gondii tachyzoites and drug treatment was initiated 3 h later. (A) and (B) show TgMe49 treated with DMSO as control for $6 \mathrm{~h}$ and $24 \mathrm{~h}$, respectively. TgMe49 treated with $0.5 \mu \mathrm{M}$ RMB060 for $6 \mathrm{~h}$ are shown in (C), $24 \mathrm{~h}$ in (D), $48 \mathrm{~h}$ in (E) and $72 \mathrm{~h}$ in (F). con = conoid; dg = dense granules; mito = mitochondrion; hmito = host cell mitochondrion; $\mathrm{n}=$ nucleus; hnuc $=$ host cell $\mathrm{nu}-$ cleus; $\mathrm{PVM}=$ parasitophorous vacuole membrane; $\mathrm{rhop}=$ rhoptries; vac = cytoplasmic vacuole. Bars in $(A)=1 \mu \mathrm{m} ;(B)=1.1 \mu \mathrm{m} ;(C)=0.8 \mu \mathrm{m} ;(D)=0.9 \mu \mathrm{m} ;(\mathrm{E})=0.5 \mu \mathrm{m} ;(\mathrm{F})=1.2 \mu \mathrm{m}$.

Due to its excellent selectivity and efficacy, RMB060 was chosen for further investigation. The alterations in parasite ultrastructure induced by these compounds were studied by TEM. T. gondii Me49 tachyzoites grown in absence of compound (Fig. 3A and B) exhibited typical features of apicomplexan parasites. They were situated in a parasitophorous vacuole, separated from the host cell cytoplasm by a parasitophorous vacuole membrane. The conoid at the apical end, and secretory organelles such as micronemes, rhoptries and dense granules were clearly discernible, and tachyzoites divided by endodyogeny. T. gondii has a single mitochondrion, which exhibits a tubule-like structure, of which only portions are visible on a single section plane. The mitochondrion is characterized by an electron-dense matrix and numerous cristae, all of which forms a clearly discernible organelle (Fig. 3A and B). 
After treatment with $500 \mathrm{nM}$ RMB060 for 6h, the mitochondrial matrix had a less electron dense appearance and dissolved cristae became evident, while the host cell mitochondria remained structurally intact (Fig. 3C). Treatment for $24 \mathrm{~h}$ led to a further deterioration of the mitochondrial matrix which appeared increasingly electron-lucent, but the outer membrane remained structurally intact, and membranous and particulate material accumulated at the interior of this organelle (Fig. 3D). Apparently, dividing parasites were visible in many instances, although there were mostly not more than two tachyzoites per vacuole. After 48h (Fig. 3E) and 72h (Fig. 3F), the mitochondrial matrix of tachyzoites appeared more electron dense and cristae became more evident again. In parallel, the parasite cytoplasm became increasingly more vacuolized, and these vacuoles were either empty or filled with particulate and often electron dense material of unknown nature. Parasitophorous vacuoles harboring several parasites were now found, especially in the specimens fixed after $72 \mathrm{~h}$ of drug treatment, indicating that tachyzoites had resumed proliferation, albeit at a much slower rate. In cultures treated with DCQ, RMB054 or RMB055 similar results could be observed (Supplementary file 3).

Under unfavorable culture conditions T. gondii tachyzoites can, in some instances, induce differentiation and undergo increased bradyzoite gene expression. To investigate whether attenuated proliferation of RMB060 treated parasites is accompanied by the expression of BAG1 (bradyzoite antigen 1), a heat shock protein and marker for physiological stress that is highly expressed in $T$. gondii bradyzoites, immunofluorescence staining of drug treated T. gondii Me49 in vitro cultures was performed (Fig. 4).

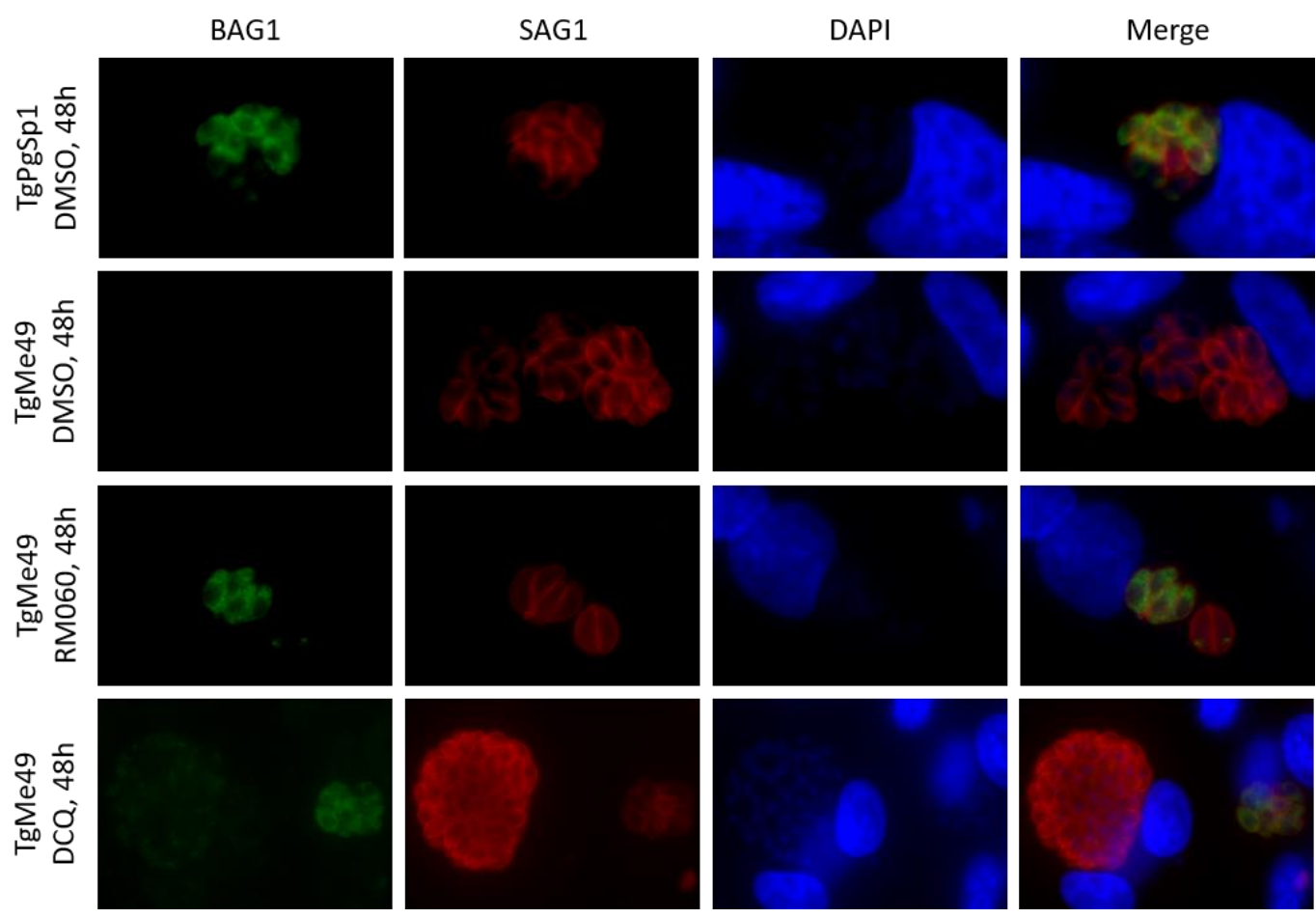

Figure 4. Immunofluorescence staining of HFF monolayers infected with T. gondii Me49 (TgMe49) tachyzoites after treatment with RMB060 and DCQ for 48h. TgMe49 treated with the corresponding amount of DMSO were used as negative control. As positive control, TgPgSp1 were fixed and processed identically. BAG1 is labelled in green, SAG1 staining is red, and nuclei are stained with DAPI.

For this, a low-passage number of T. gondii strain (TgPgSp1) with high BAG1 expression without drug treatment was used as a control, and BAG1 staining had a cytoplasmic distribution within these tachyzoites. Maintenance of T. gondii Me49 in the absence of treatment did not result in BAG1 expression, but treatment with RMB060 for 48h resulted 
in the expression of the bradyzoite marker BAG1 in the cytoplasm of some, but not all, tachyzoites (Fig. 4). DCQ also induced the expression of BAG1 after 48h (Fig. 4), but in RMB054 treated cultures, BAG1 expression was not clearly detectable (data not shown). Despite the expression of the bradyzoite marker BAG1, it was not possible to identify by TEM any other bradyzoite-like features (e.g. tissue cyst wall formation, amylopectin granules), neither in cultures that had undergone long-term treatments with RMB060 (Fig. 5A and B), nor in tachyzoites treated with DCQ for $24 \mathrm{~h}$ or for extended periods of time (Fig. $5 \mathrm{C}$ and D). For both compounds, however, we found that the structural alterations seen in the mitochondrion were still evident in tachyzoites that had undergone long-term treatments.
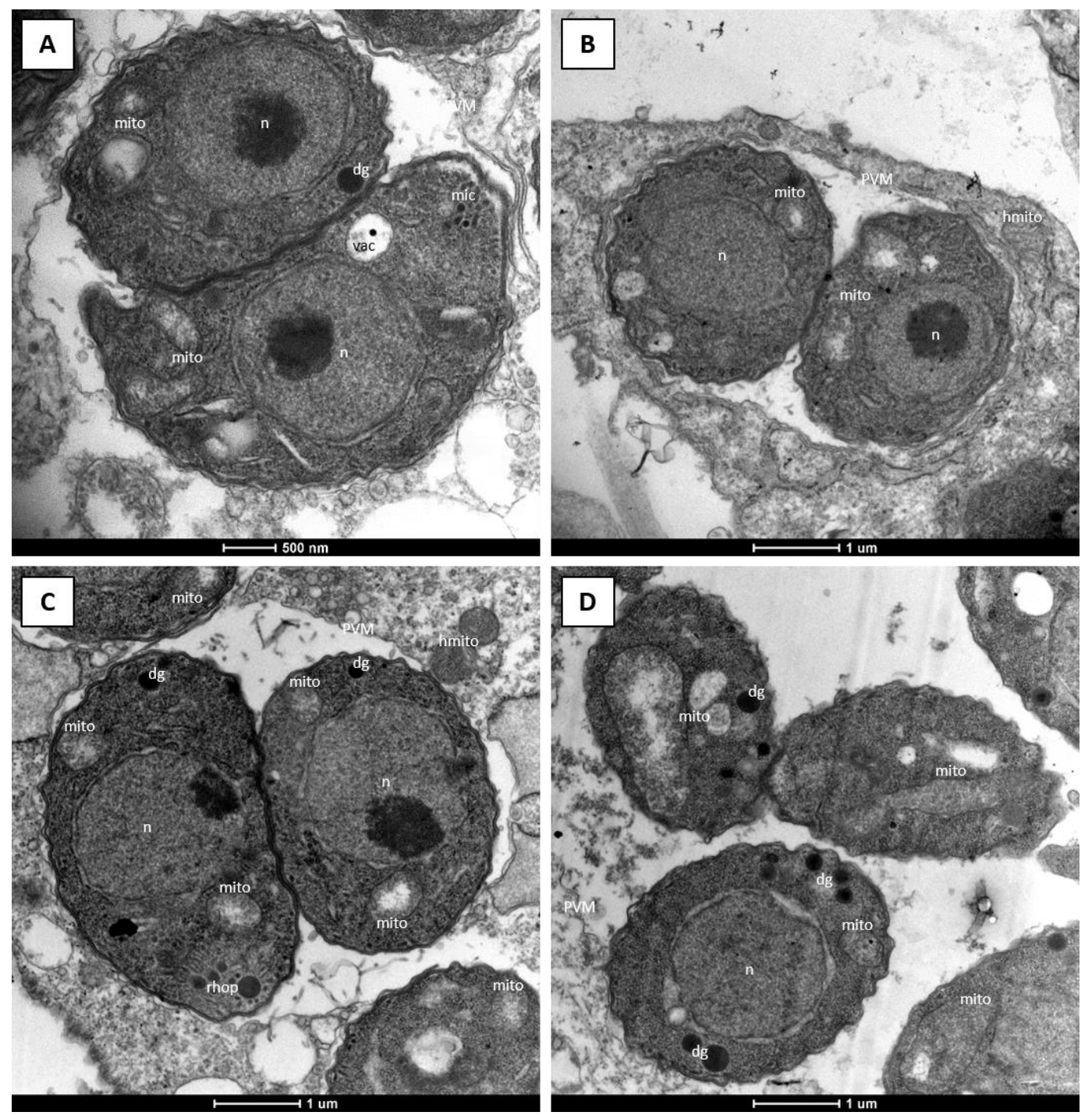

Figure 5. TEM of T. gondii Me49 tachyzoites cultured in vitro in HFF host cells. Long-term treatment with increasing concentrations of RMB060 and DCQ during 52 days, with end concentrations of 0.3 $\mu \mathrm{M}$ and $0.5 \mu \mathrm{M}$, respectively. (A) and (B) show TgMe49 treated with RMB060 and TgMe49 treated with DCQ are shown in (C) and (D). $\mathrm{dg}=$ dense granules; $\mathrm{mic}=$ micronemes; mito = mitochondrion; hmito = host cell mitochondrion; $\mathrm{n}=$ nucleus; hnuc $=$ host cell nucleus; $\mathrm{PVM}=$ parasitophorous vacuole membrane; rhop = rhoptries; vac = cytoplasmic vacuole.

\subsection{Safety assessment of DCQ and RMB060 during pregnancy in BALB/c mice}


Due to the increased neonatal mortality observed in DCQ treated pregnant mice infected with $T$. gondii, potential safety issues such as drug-induced interference in pregnancy were assessed in non-infected $\mathrm{BALB} / \mathrm{c}$ mice. The mice were mated and received 10 $\mathrm{mg} / \mathrm{kg} /$ day DCQ or RMB060 emulsified in corn oil on days 9-13 post-mating. In the control group treated with corn oil only, 4 out of 6 mice became pregnant and gave birth to 19 pups, of which 1 died within the first 2 days post-partum (neonatal mortality). In the DCQ-treated group, only 2 out of 6 mice became pregnant, and in total only 7 pups were born alive which survived until the end of the assessment. In the RMB060 group, 4 out of 6 mice became pregnant with 27 pups in total, of which 3 died within the first two days after birth. This implies that there is a strong interference in pregnancy outcome with a strongly reduced number of newborn pups due to DCQ treatment, but only minor interference in pregnancy due to RMB060 treatment (Table 3).

Table 3. Potential pregnancy interference of DCQ and RMB060 in embryo development.

\begin{tabular}{llllll}
\hline Treatment & $\begin{array}{l}\text { No. of pregnant } \\
\text { mice / no. of } \\
\text { mice }\end{array}$ & $\begin{array}{l}\text { No. of non-preg- } \\
\text { nant mice / no. } \\
\text { of mice }\end{array}$ & Litter size & $\begin{array}{l}\text { Neonatal } \\
\text { mortality }\end{array}$ & $\begin{array}{l}\text { Postnatal } \\
\text { mortality }\end{array}$ \\
\hline $10 \mathrm{mg} / \mathrm{kg}$ DCQ & $2 / 6$ & $4 / 6$ & 7 & $0 / 7$ & $0 / 7$ \\
$10 \mathrm{mg} / \mathrm{kg} \mathrm{RMB060}$ & $4 / 6$ & $2 / 6$ & 27 & $3 / 27$ & $0 / 24$ \\
Corn oil & $4 / 6$ & $2 / 6$ & 19 & $1 / 19$ & $0 / 18$ \\
\hline
\end{tabular}

\subsection{Efficacy of RMB060 in CD1 mice infected with T. gondii oocysts}

Due to the notably potent effect of RMB060 in vitro, as reflected by the very low IC 50 values and the low degree of cytotoxicity against HFF host cells, we examined the efficacy of oral RMB060 treatment $(10 \mathrm{mg} / \mathrm{kg} /$ day for 5 days $)$ in CD1 mice infected with $T$. gondii oocysts. The results of this experiment are summarized in Table 4.

Table 4. Litter size, parasite burden, neonatal and postnatal mortality rates of $T$. gondii infected and RMB060 treated mice.

\begin{tabular}{lllllllll}
\hline Treatment & Challenge & $\begin{array}{c}\text { Seropositive } \\
\text { for T. gondii }\end{array}$ & $\begin{array}{c}\text { T. gondii positive } \\
\text { non-pregnant mice }\end{array}$ & $\begin{array}{l}\text { T. gondii posi- } \\
\text { tive dams }\end{array}$ & $\begin{array}{l}\text { No of pups/ } \\
\text { no. of dams }\end{array}$ & $\begin{array}{l}\text { Neonatal } \\
\text { mortality }\end{array}$ & $\begin{array}{l}\text { Postnatal } \\
\text { mortality }\end{array}$ & $\begin{array}{l}\text { T. gondii posi- } \\
\text { tive pups }\end{array}$ \\
\hline $\begin{array}{l}10 \mathrm{mg} / \mathrm{kg} \\
\text { RMB060 }\end{array}$ & $\begin{array}{l}\text { TgShSp1 } \\
\text { oocysts }\end{array}$ & $8 / 12$ & $1 / 2$ & $7 / 10$ & $125 / 10$ & $21 / 125$ & $4 / 104$ & $62 / 100$ \\
Corn oil & TgShSp1 & $10 / 11$ & $3 / 3$ & $8 / 9$ & $113 / 9$ & $26 / 113$ & $8 / 87$ & $70 / 79$ \\
& oocysts & & & & & & & \\
Corn oil & PBS & $0 / 5$ & $0 / 3$ & $0 / 2$ & $35 / 2$ & $1 / 35$ & $0 / 34$ & $0 / 34$ \\
\hline
\end{tabular}

One dam of the RMB060 group gave birth to non-viable pups and one dam of the C+ group was found dead in the cage before she could give birth. During necropsy, 8 pups were found in the uterus, but the reason for the death of the dam was not elucidated. Overall, the treatment with RMB060 led to a slight, but non-significant, decrease of neonatal mortality ( $16.8 \%$; 21 out of 125 pups) compared to $23 \%$ ( 26 out of 113 pups) in the non-treated but infected C+ group (Fig. 6A). In the RMB060 group 4 out of the 104 remaining pups (3.8\%) died during the first 11 days of the postnatal phase, while 8 out of the remaining 87 pups $(9.2 \%)$ died in the $C+$ group (Table 4$)$. Of the 100 surviving pups in the RMB060 group, 62 were tested PCR-positive for T. gondii in the brain (62\%), and in the C+ 
group 70 of the 79 surviving pups (89\%) were tested PCR-positive. In the adult mice (including dams and non-pregnant mice) brain infection was detected in 8 out of 12 mice in the RMB060 group and in 11 out of 12 mice in the $C+$ group (Table 4). The mean values of the parasite load were slightly higher in the $\mathrm{C}+$ group compared to the RMB060 group in dams and non-pregnant mice, but there was no significant difference (Fig. 6B and C).
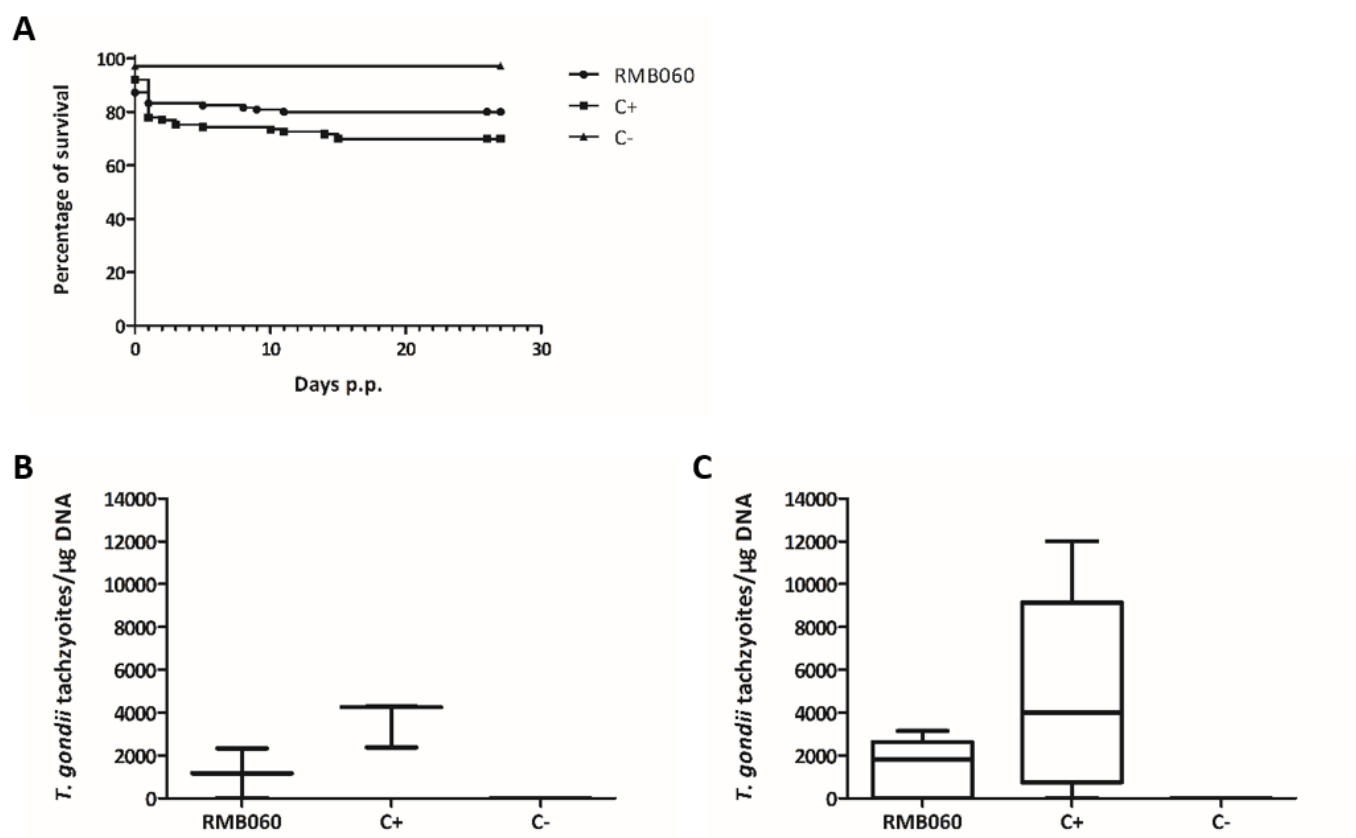

Figure 6. RMB060 treatment in the pregnant toxoplasmosis mouse model. Survival curves of pups (A) and cerebral parasite burden of non-pregnant mice (B) and dams (C). Survival rates were plotted in Kaplan-Meier graphs at each time point and curves were compared by the Log-rank (MantelCox) test. No statistically significant differences were observed between the survival curves of the RMB060 group and the C+ group. CD1 mice were infected with $100 \mathrm{TgShSp} 1$ oocysts and treated with $10 \mathrm{mg} / \mathrm{kg}$ RMB060, while C+ was infected and treated only with corn oil. C- was not infected and treated with corn oil alone. 4 weeks p.p. all mice were euthanized, brains were aseptically collected, and cerebral parasite burden was quantified by real-time PCR. The values are depicted as box plots and parasite burden between groups were compared by the Kruskal-Wallis test, followed by the Mann-Whitney-U test. No statistically significant differences in the cerebral parasite burden were observed between RMB060-treated mice compared to the C+ group (neither in non-pregnant mice nor in dams).

In all $T$. gondii brain positive mice, increased IgG serum-levels were recorded. In nonpregnant mice, IgG titers of the $\mathrm{C}+$ group showed higher RIPC values than those of the RMB060 group, but in dams the IgG titer of both groups were in the same range (Supplementary file 4 ). Thus, despite highly promising IC 50 values and the low cytotoxicity seen in vitro, RMB060 treatment did not protect all dams from $T$. gondii infection and only a low increase in pup survival compared to the $\mathrm{C}+$ group could be achieved.

\section{Discussion}

Quinolones are a group of compounds that are active against a wide array of bacteria and parasites [19]. They are in clinical use as antibiotics, and the anti-malarial activity of these compounds has been known for many years [20-24]. Quinolones also possess activity against $T$. gondii, and especially some endochin-like quinolones, applied alone or in combination with pyrimethamine, were shown to exhibit promising effects against acute 
and also latent toxoplasmosis [25-27]. DCQ is one of the most prominent and widely used quinolones. It is frequently applied in chicken and ruminants against coccidiosis, caused by different Eimeria species that colonize and cause damage in the gastrointestinal tract. A drawback of DCQ is its exceedingly poor aqueous solubility, which renders the compound less useful for combating tissue-dwelling parasites.

In this study, we investigate the efficacies of DCQ and three quinoline-O-carbamate derivatives RMB055, RMB054 and RMB060 against T. gondii tachyzoites. All three derivatives were prepared from DCQ in an attempt to improve the drug-likeness of the DCQ scaffold by adding groups that improve the physicochemical properties of the drug [18]. RMB060 was highly active against the liver stage of Plasmodium berghei malaria parasites and all three derivatives were also highly active against multi-drug-resistant strains of $P$. falciparum, with no or very minor cytotoxicity reported in human fetal lung fibroblasts and human foreskin fibroblasts [18].

DCQ was reported previously to inhibit $T$. gondii proliferation in vitro with an IC 50 value of $12 \mathrm{nM}$. Like other quinolones, the drug affects the cytochrome $b c_{1}$ complex-mediated electron transport in the mitochondrion [15]. The cytochrome $b c$-complex transfers electrons from coenzyme Q to cytochrome $c$ [28]. DCQ blocks this transfer, thereby causing the relocation of electrons to other biomolecules generating free radicals and reactive oxygen species (ROS), which are toxic to the parasite. More specifically, DCQ blocks the quinol reductase site of the parasite mitochondrial cytochrome $b c 1$ complex and inhibits parasite mitochondrial electron transport chain $[29,30]$.

In our study, the $\mathrm{IC}_{50}$ for DCQ was found to range from $1.1-4.7 \mathrm{nM}$, depending on the time point of initiation of treatment. Thus, we confirmed previous findings [15] that besides impairing intracellular proliferation DCQ also has an effect on extracellular tachyzoites. This is in accord with a report on the effect of DCQ on the related apicomplexan parasite Besnoitia besnoiti [12], but differs to results of earlier studies with Neospora caninum, where DCQ only showed a minimal effect against extracellular zoites [31]. Against the apicomplexan parasite Sarcocystis neurona, DCQ displayed IC 50 values for merozoites in the range of $0.6-1.1 \mathrm{nM}$ [32], and had parasiticidal activity against S. neurona schizonts on a 10 day treatment at $240 \mathrm{nM}$. Notably, long-term treatment assays in our study showed that DCQ, applied at concentrations of up to $500 \mathrm{nM}$ per day for 24 days was not parasiticidal. Whilst a report of an earlier study of treatment of infected cultures with $240 \mathrm{nM}$ DCQ led to tissue cyst formation of the T. gondii RH strain [33], we were not able to detect any structural features associated with formation of bradyzoites by TEM. Whilst use of different strains, culture conditions, host cells and treatment regimens may account for these differences, it is apparent that the activity of DCQ in these protracted assays do not at all correlate with the indications of potency provided by the incipient assays in vitro against T. gondii.

DCQ had been previously examined in efficacy studies in vivo in different mouse models for Plasmodium and Cryptosporidium infection [34-36] without causing any serious adverse effects. Thus, we assessed the efficacy of DCQ in vivo in a pregnant mouse model for T. gondii ShSp1 oocyst infection. However, DCQ treatment of T. gondii infected pregnant mice at $10 \mathrm{mg} / \mathrm{kg} /$ day for 5 days resulted in a detrimental outcome. While fertility was not affected by the drug - 92 pups were born from 8 dams in both, the DCQ-treated and the C+ group - the rate of neonatal mortality was almost twice as high in the DCQtreated group. In addition, all pups of the DCQ group that survived until 30 days postpartum were T. gondii PCR-positive, while in the C+ group 20 of 55 pups were PCR-negative. This finding is surprising, as DCQ is not known to have embryotoxic or teratogenic effects [13]. However, most, if not all, published studies employing DCQ were carried out in non-pregnant mice, and the drug is specifically marketed for the treatment of gastrointestinal coccidiosis in cattle, small ruminants and poultry. Pharmacokinetic studies in 
milking cows that received $0.5 \mathrm{mg} / \mathrm{kg}$ DCQ had shown that the compound was well absorbed and reached maximum plasma concentrations of $2 \mu \mathrm{M}$ [14], which was well above the $\mathrm{IC}_{50}$ value for $T$. gondii. DCQ is also marketed for use in pregnant ewes for prophylaxis of Toxoplasma-induced abortion, with a recommended dose of $2 \mathrm{mg} / \mathrm{kg}$ during the last 14 days of pregnancy without any obvious adverse effects on pregnancy outcome. Possibly the timing of DCQ treatment could have had an impact in this study. Teratogenic effects are most problematic for the fetus during the first trimester of development [37], during which the fetal tissue is undergoing rapid cell proliferation [38]. The distinct anatomical and physiological dissimilarities between ruminant and mouse placenta could also account for the observed effects in this study [39], together with other differences such as species-dependent bioavailability, metabolic stability, systemic exposure, and other pharmacokinetic properties. Overall, in this mouse model, DCQ treatment appeared non-efficacious, caused serious adverse effects and led to increased neonatal pup mortality.

Of the three quinoline-O-carbamate derivatives of DCQ investigated in this study, dose-response assessments in vitro showed that RMB060 in particular had highly favorable properties, with a selectivity index of $>140,000$ when the drug was applied concomitantly to infection, and $>14,000$ upon addition of the compound to intracellular parasites at $3 \mathrm{~h}$ post-infection. Ultrastructural investigations on the impact of RMB060 treatment on T. gondii tachyzoites cultured in HFF showed that the compound primarily induced alterations in the tachyzoite mitochondrion and affected especially the matrix and the cristae. This is similar to observations reported with other drugs that target the cytochrome $b c_{1}$ complex in apicomplexan parasites, such as in DCQ- and buparvaquone-treated Besnoitia besnoiti tachyzoites [12,40], and in endochin-like quinolone-treated N. caninum tachyzoites [41]. Interestingly, despite the low IC $_{50}$ values determined in short-term growth assays (0.07-0.7 nM), exposure to the drug for longer timespans showed that T. gondii tachyzoites readily adapted to concentrations that were up to 4286 -fold the $\mathrm{IC}_{50}$, resumed proliferation (albeit at a lower rate than non-treated parasites) and formed lysis plaques. This underlines the impressive adaptive potential of T. gondii, as seen previously with other drugs, such as dicationic pentamidine derivatives [42]. On one hand, this adaptive potential could be based on true resistance formation, for example, point mutations in the cytochrome $b$ gene, as seen in buparvaquone resistant Theileria [43]. On the other hand, adaptation to increased drug concentrations could also be based on an altered gene expression pattern, such as increased expression of genes coding for components of the Toxoplasma detoxification machinery, e.g. ATP-binding cassette (ABC) transporters, which represent an important family of membrane proteins involved in drug resistance and other biological activities [44]. Alternatively, parasites develop an enhanced adaptation to oxidative stress.

Interestingly, although we found that treatment with RMB060 in vitro induced the expression of the bradyzoite marker BAG1, TEM of parasite cultures submitted to longterm treatment with RMB060 did not reveal the presence of additional structural features of bradyzoites. Thus, no differentiation into cyst-forming bradyzoites took place. Nevertheless, the alterations in the mitochondrial matrix appeared to be persistently present also in drug-adapted parasites undergoing prolonged treatment with each of RMB060 and DCQ. We hypothesize that the dissolution of the mitochondrial matrix and the cristae could constitute an escape mechanism for the parasites to overcome the detrimental effects of the drug that acts on the cytochrome $b c 1$ complex. In the presence of intact cristae, this would induce free radical and ROS formation, resulting in a parasitostatic, but not parasiticidal, effect. Since $T$. gondii tachyzoites exhibiting such altered mitochondria are fully viable, their energy metabolism is most likely dependent on glycolysis. Moreover, the intermediate metabolites obtained from intact mitochondria must be scavenged from 
the host cell. Certainly, more research is needed to elucidate this mechanism that leads to this marked tolerance to increased drug concentrations.

In terms of drug efficacy in vivo, a parasitostatic effect could be an advantage. If the parasite is kept at a subclinical level, the antigenic stimulus might still be sufficiently high to provide a sustained immune response, potentially preventing reinfection after recovering from the acute stage, as it has been postulated for other compounds such as bumped kinase inhibitors (BKIs) $[45,46]$. We thus assessed the efficacy of RMB060 in the pregnant T. gondii ShSp1 oocyst infection model. However, although treatment of T. gondii infected pregnant mice at $10 \mathrm{mg} / \mathrm{kg} /$ day for 5 days with RMB060 showed better results than DCQ, the outcome was not as expected based on the promising in vitro efficacy. The fertility was not affected by the drug - 125 pups from 10 dams were born in the RMB060 group, and 113 pups from 9 dams in the $\mathrm{C}+$ group. Also, the neonatal and postnatal mortality was lower in the RMB060 treatment group - $16.8 \%$ and $3.8 \%$ compared to $23 \%$ and $2.9 \%$ in the $\mathrm{C}+$ group, respectively. Likewise, treatment reduced the cerebral parasite burden as assessed by the number of $T$. gondii tachyzoites per $\mu \mathrm{g}$ DNA in all groups including nonpregnant mice, dams and pups. Nevertheless, vertical transmission could not be prevented and all pups from T. gondii PCR-positive dams that survived until 30 days postpartum tested PCR-positive for T. gondii in the brain in both, the RMB060-treated and the C+ groups. Overall, in this mouse model, RMB060 showed a tendency to be active against Toxoplasma infection in non-pregnant mice and dams, though vertical transmission could not be prevented. Finally, it must be pointed out that definitive evaluation of the effects of RMB060 must await pharmacokinetic studies of the compound. It is structurally related to the $\mathrm{O}$-quinoline carbonate ELQ-337 prepared from the antimalaria-active quinolone ELQ-300, wherein the derivative acts as a prodrug for the quinolone. Upon oral administration in a mouse model the parent drug ELQ is formed without detectable persistence of the intact prodrug in murine plasma, however, greatly enhanced levels of ELQ-300 are observed through administration of ELQ-337 [21]. Likewise, the quinoline-O-carbonate prodrug ELQ-334 has been prepared from the quinolone ELQ-316 that is active against the apicomplexan parasite Neospora caninum - here also, application of the prodrug results in enhanced plasma levels of the parent quinolone [47].

\section{Materials and Methods}

\subsection{Cell culture equipment and media, biochemicals, and compounds}

Unless stated otherwise, all cell culture devices were purchased from Sarstedt (Sevelen, Switzerland), media from Gibco-BRL (Zürich, Switzerland) and biochemicals from Sigma (St. Louis, MO, USA). DCQ was kindly provided by Prof. Gilles Gasser, Chimie ParisTech - PSL, University of Paris. RMB054, RMB055, and RMB060 were synthesized and purified as previously described [18]. All compounds were received as powder. For in vitro studies, stock solutions of 1 and $10 \mathrm{mM}$ of the compounds in dimethylsulfoxide (DMSO) were prepared and stored at $-20^{\circ} \mathrm{C}$.

\subsection{Host cells and parasites}

Human foreskin fibroblasts (HFF; PCS-201-010 ${ }^{\mathrm{TM}}$ ) were cultured as described [45]. Tachyzoites of T. gondii $\beta$-gal (Tg- $\beta$-gal) constitutively expressing $\beta$-galactosidase were 
kindly provided by Prof. David Sibley, Washington University, St. Louis, USA, the T. gondii Me49 (TgMe49) strain was obtained from Dr. Furio Spano, Istituto Superiore di Sanita, Rome, Italy, and a low-passage number Spanish T. gondii Pig isolate (TgPgSp1) was obtained from SALUVET-Innova (ETCU-UCM), Madrid [48]. They were maintained as previously described [46]. T. gondii oocysts of the type II isolate TgShSp1 [49] were received from SALUVET, Complutense University of Madrid, Spain, and stored at $4^{\circ} \mathrm{C}$ until use.

\subsection{Cytotoxicity, anti-T. gondii efficacy assessments and long-term drug treatment in vitro}

HFF cytotoxicity assessments and $\mathrm{IC}_{50}$ determinations using cultures of Tg- $\beta$-gal tachyzoites grown in HFF were carried out as described previously [18,50]. IC $C_{50}$ values were calculated with the logit-log-transformation of the relative growth and subsequent regression analysis was done with the corresponding software tool contained in Microsoft Excel software package (Microsoft, Seattle, WA). For the long-term treatments, HFF grown in T25 culture flasks were infected with $5 \times 10^{5} \mathrm{TgMe} 49$ tachyzoites, and after $4.5 \mathrm{~h}$ $0.5 \mu \mathrm{M}$ DCQ, RMB054 or RMB060 were added. Infected cultures treated with the highest corresponding concentration of DMSO (0.5\%) served as controls. Prolonged treatments for up to 24 days were carried out, with addition of fresh medium containing the respective drug every 3-4 days. Cultures were inspected by light microscopy on a daily basis. On days 3, 6, 9, 13, 16, 20 and 24, the compound-containing medium was removed and parasites were maintained without drug pressure until host cell lysis (plaque formation) was evident.

\subsection{Microscopy}

For transmission electron microscopy (TEM), HFF grown in T25 culture flasks were infected with $10^{7} \mathrm{TgMe} 49$ tachyzoites and incubated for $3 \mathrm{~h}$ at $37^{\circ} \mathrm{C}$ and $5 \% \mathrm{CO}_{2}$. Subsequently, cultures were exposed to continuous treatment of $6 \mathrm{~h}, 24 \mathrm{~h}, 48 \mathrm{~h}$, and $72 \mathrm{~h}$ with 0.5 $\mu \mathrm{M}$ DCQ, RMB054 or RMB060, and $1 \mu \mathrm{M}$ RMB055. Infected cultures treated with DMSO served as controls. TEM preparations were performed as described earlier [46,50,51]. Samples were observed on a Philips CM 12 or a FEI Tecnai Spirit BioTwin TEM, both operating at $80 \mathrm{kV}$.

For immunofluorescence microscopy, $4 \times 10^{4} \mathrm{HFF}$ were grown on glass coverslips for $24 \mathrm{~h}$ to form a sub-confluent monolayer and were exposed to $1.2 \times 10^{5} \mathrm{TgMe} 49$ tachyzoites during $4 \mathrm{~h}$ at $37^{\circ} \mathrm{C}$ and $5 \% \mathrm{CO}_{2}$. The medium was replaced and supplemented with $20 \mathrm{nM}$ DCQ and RMB060, or medium containing DMSO as control. Cultures infected with TgPgSp1 (low passage number) served as positive control for BAG1 (bradyzoite antigen 1) expression. Infected cells were cultured for $16 \mathrm{~h}, 24 \mathrm{~h}$, and $48 \mathrm{~h}$ and fixed and labelled for immunofluorescence staining as described previously [50,51]. A polyclonal rabbit antiBAG1 antiserum was applied at 1:200 dilution, followed by a goat-anti-rabbit fluoresceinisothiocyanate conjugate (1:300), the monoclonal mouse anti-TgSAG1 antibody was diluted (1:100), followed by goat anti-mouse conjugated to tetramethylrhodamine-isothiocyanate at 1:300. Subsequently, samples were mounted in H-1200 Vectashield mounting medium (Vector Laboratories, Burlingame, CA, USA) containing 4,6-diamidino-2-phenylindole and were viewed on a Nikon E80i fluorescence microscope. Processing of images was performed using Openlab 5.5.2 (Improvision, PerkinElmer, Waltham, MA, USA) and the ImageJ software.

\subsection{Ethics statement}


Animal experiments were approved by the Animal Welfare Committee of the Canton of Bern under the license BE117/20. CD1 and BALB/c mice were purchased from Charles River (Sulzberg, Germany) at 6 weeks of age, and were maintained in a common room under controlled temperature and a $14 \mathrm{~h} / 10 \mathrm{~h}$ dark/light cycle, with food and water ad libitum. Prior to the experiment, they were housed two weeks in the facility for adaptation. The animals were handled in strict accordance with practices to minimize suffering.

\subsection{Pregnancy interference test in $B A L B / c$ mice}

18 female and 9 male BALB/C mice, all 8 weeks of age, were used. The females were oestrus-synchronized for 3 days by the Whitten effect and were mated by housing 2 females and 1 male for $72 \mathrm{~h}$ in one cage. Males were removed after mating and females were randomly assigned to 3 experimental groups of 6 mice each: DCQ; RMB060; placebo. On day 9-13 post-mating, DCQ and RMB060 were supplied at $10 \mathrm{mg} / \mathrm{kg} /$ day in $100 \mu \mathrm{l}$ corn oil by oral gavage. The placebo group only received corn oil. Mice were observed and weighed on several days and on day 18 post-mating pregnant females were separated into single cages. Dams gave birth between day 20-22. Dams and pups were observed daily and data on fertility, litter size, neonatal and postnatal mortality was recorded for the following 2 weeks. All mice were euthanized in a chamber by isoflurane/ $\mathrm{CO}_{2}$ inhalation.

\subsection{DCQ efficacy assessment in CD1 mice orally infected with TgShSp1 oocysts}

29 female and 15 male CD1 mice, all 8 weeks of age, were used. Oestrus-synchronization and mating was carried out as described under 4.6. Subsequently, females were distributed randomly to 3 experimental groups: DCQ, DCQ + infection $(n=12) ; C+$, corn oil + infection $(n=12)$; C-, only corn oil $(n=5)$. Infection was performed with $100 \mathrm{TgShSp} 1$ oocysts at day 7 post-mating by oral gavage, the C- group received PBS. The treatment with DCQ suspended in corn oil at $10 \mathrm{mg} / \mathrm{kg} /$ day for 5 days or only with corn oil was initiated at 2 days post-infection. At day 18 post-mating pregnant mice were distributed into single cages and non-pregnant mice were housed together with 3-4 animals per cage. Dams gave birth between day 20-22, and clinical status, litter size, neonatal and postnatal mortality were recorded daily. 4 weeks post-partum (p.p.) all mice were euthanized in a chamber by isoflurane/ $\mathrm{CO}_{2}$ inhalation. Blood and brain samples were collected. Total IgG was measured in T. gondii infected mice by ELISA [49].

\subsection{RMB060 efficacy assessment in CD1 mice orally infected with TgShSp1 oocysts}

8 week-old CD1 mice, 29 females and 15 males, were used. After oestrus-synchronization and mating, females were randomly distributed to 3 experimental groups: RMB060, RMB060 + infection $(n=12) ; C+$, corn oil + infection $(n=12) ; C-$, only corn oil $(n=5)$. Infection was carried out at day 7 post-mating with $100 \mathrm{TgShSp} 1$ oocysts with the Cgroup receiving only PBS. Treatments, separation of pregnant and non-pregnant mice, and monitoring were performed as described in section 4.7. All mice were euthanized 4 weeks p.p. by isoflurane/CO . Blood and brain samples were collected. Total $\mathrm{IgG}$ was measured in T. gondii infected mice by ELISA [49]. 
Quantification of the cerebral parasite load in non-pregnant mice, dams and pups was carried out with an established real-time PCR method for the detection of T. gondii [52]. The NucleoSpin DNA RapidLyze Kit (Macherey-Nagel, Oensingen, Switzerland) was used for DNA purification according to the standard protocol and DNA concentrations were quantified by the QuantiFluor double-stranded DNA (dsDNA) system (Promega, Madison, WI, USA). Quantitative real-time PCR was performed with the Light Cycler (Roche, Basel, Switzerland), and the parasite load was calculated by including a standard curve of DNA samples from 1'000, 100, and $10 \mathrm{~T}$. gondii tachyzoites per run $[50,53]$.

\subsection{Statistical analysis}

Graph creation and statistical analysis was performed in GraphPad Prism version 5.0 (GraphPad Software, La Jolla, CA, USA). Cerebral parasite burdens were compared between groups by the non-parametric Kruskal-Wallis test, followed by Mann-Whitney-U test. The pup mortality along time was depicted by plotting survival events at each time point in Kaplan-Meier graphs and survival curves were compared by the Log-rank (Mantel-Cox) test.

\section{Conclusions}

In conclusion, DCQ and its derivatives are very active against $T$. gondii in vitro. However, results of the experiments in vivo were disappointing in that treatment with DCQ did not clear parasitaemia and had detrimental effects on pup survival. Although RMB060 reduced the infection in adult mice, vertical transmission could not be prevented. Overall, whilst rapidly proliferating tachyzoites are readily expunged by the drugs as indicated by the short-term growth assays in vitro, long-term exposure results in growth inhibition, but no parasiticidal activity is detected, indicating that $T$. gondii is able to adapt to drug pressure. The outcome of the current work illustrates the need now for rational development of drugs, and especially drug combinations, that can target the quiescent tachyzoites and subsequent stages.

Supplementary Materials: The following are available online at www.mdpi.com/xxx/s1. Figure S1: IC50 dose-response curves for T. gondii tachyzoites grown in HFF treated with DCQ, RMB054, RMB055 and RMB060. Figure S2: T. gondii IgG antibody titers of non-pregnant mice and dams measured from serum collected from mice treated with DCQ or not. Figure S3: TEM of T. gondii-infected HFF treated with DCQ, RMB054 and RMB055. Figure S4: T. gondii IgG antibody titers of non-pregnant mice and dams measured from serum collected from mice treated with RMB060 or not.

Author Contributions: For research articles with several authors, a short paragraph specifying their individual contributions must be provided. The following statements should be used "Conceptualization, J.R and A.H; methodology, J.R., D.I., N.A., K.H., V.B., R.B., I.F.; R.S-S.; A.H. and R.K.H.; validation, A.H., R.K.H.; J.R., D.I., N.A. and A.H.; investigation, J.R., D.I. and A.H.; resources, A.H. and R.K.H.; writing - original draft preparation, J.R.; writing - review and editing, J.R.; L-M.O-M.; I.F.; A.H. and R.K.H.; visualization, J.R. and A.H.; supervision, A.H.; project administration, A.H. and R.K.H.; funding acquisition, A.H. and R.K.H. All authors have read and agreed to the published version of the manuscript."

Funding: This research was funded by the Swiss National Science Foundation, grant number 310030_184662. The APC was funded by the Swiss National Science Foundation. R.S-S was financially supported by the Community of Madrid (PLATESA2-CM, P2018/BAA-4370)

Institutional Review Board Statement: Animal experiments were approved by the Animal Welfare Committee of the Canton of Bern under the license BE117/20. License validity 27.11.2020 - 27.11.2023. 
Data Availability Statement: Data are made available as supplementary datasets (see above).

Acknowledgments: We thankfully acknowledge Prof. David Sibley, Washington University of St. Louis, for providing the T. gondii- $\beta$-gal strain, and Prof. Dominique Soldati for providing antibodies directed against SAG1.

Conflicts of Interest: The authors declare no conflict of interest. The funders had no role in the design of the study; in the collection, analyses, or interpretation of data; in the writing of the manuscript, or in the decision to publish the results.

\section{References}

1. Djurković-Djaković, O.; Dupouy-Camet, J.; Van der Giessen, J.; Dubey, J.P. Toxoplasmosis: Overview from a One Health Perspective. Food Waterborne Parasitol. 2019, 15, e00054, doi:10.1016/j.fawpar.2019.e00054.

2. Dubey, J.P. Outbreaks of Clinical Toxoplasmosis in Humans: Five Decades of Personal Experience, Perspectives and Lessons Learned. Parasit. Vectors 2021, 14, 263, doi:10.1186/s13071-021-04769-4.

3. Melchor, S.J.; Ewald, S.E. Disease Tolerance in Toxoplasma Infection. Front. Cell. Infect. Microbiol. 2019, 9, 185, doi:10.3389/fcimb.2019.00185.

4. Alday, P.H.; Doggett, J.S. Drugs in Development for Toxoplasmosis: Advances, Challenges, and Current Status. Drug Des. Devel. Ther. 2017, Volume11, 273-293, doi:10.2147/DDDT.S60973.

5. Wei, H.-X.; Wei, S.-S.; Lindsay, D.S.; Peng, H.-J. A Systematic Review and Meta-Analysis of the Efficacy of Anti-Toxoplasma Gondii Medicines in Humans. PLOS ONE 2015, 10, e0138204, doi:10.1371/journal.pone.0138204.

6. Meneceur, P.; Bouldouyre, M.-A.; Aubert, D.; Villena, I.; Menotti, J.; Sauvage, V.; Garin, J.-F.; Derouin, F. In Vitro Susceptibility of Various Genotypic Strains of Toxoplasma Gondii to Pyrimethamine, Sulfadiazine, and Atovaquone. Antimicrob. Agents Chemother. 2008, 52, 1269-1277, doi:10.1128/AAC.01203-07.

7. Lindsay, D.S.; Dubey, J.P. Neosporosis, Toxoplasmosis, and Sarcocystosis in Ruminants: An Update. Vet. Clin. North Am. Food Anim. Pract. 2020, 36, 205-222, doi:10.1016/j.cvfa.2019.11.004.

8. Andrews, K.T.; Fisher, G.; Skinner-Adams, T.S. Drug Repurposing and Human Parasitic Protozoan Diseases. Int. J. Parasitol. Drugs Drug Resist. 2014, 4, 95-111, doi:10.1016/j.ijpddr.2014.02.002.

9. McFarland, M.M.; Zach, S.J.; Wang, X.; Potluri, L.-P.; Neville, A.J.; Vennerstrom, J.L.; Davis, P.H. Review of Experimental Compounds Demonstrating Anti-Toxoplasma Activity. Antimicrob. Agents Chemother. 2016, 60, 7017-7034, doi:10.1128/AAC.01176-16.

10. Secrieru, A.; Costa, I.C.C.; O’Neill, P.M.; Cristiano, M.L.S. Antimalarial Agents as Therapeutic Tools Against Toxoplasmosis-A Short Bridge between Two Distant Illnesses. Molecules 2020, 25, 1574, doi:10.3390/molecules25071574.

11. Sánchez-Sánchez, R.; Vázquez, P.; Ferre, I.; Ortega-Mora, L.M. Treatment of Toxoplasmosis and Neosporosis in Farm Ruminants: State of Knowledge and Future Trends. Curr. Top. Med. Chem. 2018, 18, 1304-1323, doi:10.2174/1568026618666181002113617.

12. Jiménez-Meléndez, A.; Rico-San Román, L.; Hemphill, A.; Balmer, V.; Ortega-Mora, L.M.; Álvarez-García, G. Repurposing of Commercially Available Anti-Coccidials Identifies Diclazuril and Decoquinate as Potential Therapeutic Candidates against Besnoitia Besnoiti Infection. Vet. Parasitol. 2018, 261, 77-85, doi:10.1016/j.vetpar.2018.08.015.

13. Bampidis, V.; Azimonti, G.; Bastos, M. de L.; Christensen, H.; Dusemund, B.; Kouba, M.; Kos Durjava, M.; López-Alonso, M.; López Puente, S.; Marcon, F.; et al. Safety and Efficacy of Deccox® (Decoquinate) for Chickens for Fattening. EFSA J. 2019, 17, doi:10.2903/j.efsa.2019.5541.

14. Quintero-de Leonardo, J.; Rosiles, R.; Bautista, J.; González-Monsón, N.; Sumano, H. Oral Pharmacokinetics and Milk Residues of Decoquinate in Milking Cows. J. Vet. Pharmacol. Ther. 2009, 32, 403-406, doi:10.1111/j.1365-2885.2008.01049.x.

15. Ricketts, A.P.; Pfefferkorn, E.R. Toxoplasma Gondii: Susceptibility and Development of Resistance to Anticoccidial Drugs In Vitro. Antimicrob. Agents Chemother. 1993, 37, 2358-2363, doi:10.1128/AAC.37.11.2358. 
16. Buxton, D.; Brebner, J.; Wright, S.; Maley, S.W.; Thomson, K.M.; Millard, K. Decoquinate and the Control of Experimental Ovine Toxoplasmosis. Vet. Rec. 1996, 138, 434-436, doi:10.1136/vr.138.18.434.

17. Pogany, S.; Tanol, M.; Baltezor, M.J. Decoquinate Prodrugs. 47.

18. Beteck, R.M.; Seldon, R.; Coertzen, D.; van der Watt, M.E.; Reader, J.; Mackenzie, J.S.; Lamprecht, D.A.; Abraham, M.; Eribez, K.; Müller, J.; et al. Accessible and Distinct Decoquinate Derivatives Active against Mycobacterium Tuberculosis and Apicomplexan Parasites. Commun. Chem. 2018, 1, 62, doi:10.1038/s42004-018-0062-7.

19. Andriole, V.T. The Quinolones: Past, Present, and Future. Clin. Infect. Dis. 2005, 41, S113-S119, doi:10.1086/428051.

20. Cross, R.M.; Flanigan, D.L.; Monastyrskyi, A.; LaCrue, A.N.; Sáenz, F.E.; Maignan, J.R.; Mutka, T.S.; White, K.L.; Shackleford, D.M.; Bathurst, I.; et al. Orally Bioavailable 6-Chloro-7-Methoxy-4 $(1 H)$-Quinolones Efficacious against Multiple Stages of Plasmodium. J. Med. Chem. 2014, 57, 8860-8879, doi:10.1021/jm500942v.

21. Miley, G.P.; Pou, S.; Winter, R.; Nilsen, A.; Li, Y.; Kelly, J.X.; Stickles, A.M.; Mather, M.W.; Forquer, I.P.; Pershing, A.M.; et al. ELQ-300 Prodrugs for Enhanced Delivery and Single-Dose Cure of Malaria. Antimicrob. Agents Chemother. 2015, 59, 55555560, doi:10.1128/AAC.01183-15.

22. Ryley, J.F.; Peters, W. The Antimalarial Activity of Some Quinolone Esters. Ann. Trop. Med. Parasitol. 1970, 64, 209-222, doi:10.1080/00034983.1970.11686683.

23. Stickles, A.M.; Smilkstein, M.J.; Morrisey, J.M.; Li, Y.; Forquer, I.P.; Kelly, J.X.; Pou, S.; Winter, R.W.; Nilsen, A.; Vaidya, A.B.; et al. Atovaquone and ELQ-300 Combination Therapy as a Novel Dual-Site Cytochrome Bc 1 Inhibition Strategy for Malaria. Antimicrob. Agents Chemother. 2016, 60, 4853-4859, doi:10.1128/AAC.00791-16.

24. Beteck, R.M.; Smit, F.J.; Haynes, R.K.; N’Da, D.D. Recent Progress in the Development of Anti-Malarial Quinolones. Malar. J. 2014, 13, 339, doi:10.1186/1475-2875-13-339.

25. Doggett, J.S.; Schultz, T.; Miller, A.J.; Bruzual, I.; Pou, S.; Winter, R.; Dodean, R.; Zakharov, L.N.; Nilsen, A.; Riscoe, M.K.; et al. Orally Bioavailable Endochin-Like Quinolone Carbonate Ester Prodrug Reduces Toxoplasma Gondii Brain Cysts. Antimicrob. Agents Chemother. 2020, 64, doi:10.1128/AAC.00539-20.

26. Doggett, J.S.; Nilsen, A.; Forquer, I.; Wegmann, K.W.; Jones-Brando, L.; Yolken, R.H.; Bordón, C.; Charman, S.A.; Katneni, K.; Schultz, T.; et al. Endochin-like Quinolones Are Highly Efficacious against Acute and Latent Experimental Toxoplasmosis. Proc. Natl. Acad. Sci. 2012, 109, 15936-15941, doi:10.1073/pnas.1208069109.

27. Martynowicz, J.; Doggett, J.S.; Sullivan, Jr., W.J. Efficacy of Guanabenz Combination Therapy against Chronic Toxoplasmosis across Multiple Mouse Strains. Antimicrob. Agents Chemother. 2020, 64, 11, doi:10.1128/AAC.00539-20.

28. Mitchell, P. Protonmotive Redox Mechanism of the Cytochrome $b-c 1$ Complex in the Respiratory Chain: Protonmotive Ubiquinone Cycle. FEBS Lett. 1975, 56, 1-6, doi:10.1016/0014-5793(75)80098-6.

29. Nam, T.; McNamara, C.W.; Bopp, S.; Dharia, N.V.; Meister, S.; Bonamy, G.M.C.; Plouffe, D.M.; Kato, N.; McCormack, S.; Bursulaya, B.; et al. A Chemical Genomic Analysis of Decoquinate, a Plasmodium Falciparum Cytochrome $b$ Inhibitor. ACS Chem. Biol. 2011, 6, 1214-1222, doi:10.1021/cb200105d.

30. da Cruz, F.P.; Martin, C.; Buchholz, K.; Lafuente-Monasterio, M.J.; Rodrigues, T.; Sönnichsen, B.; Moreira, R.; Gamo, F.-J.; Marti, M.; Mota, M.M.; et al. Drug Screen Targeted at Plasmodium Liver Stages Identifies a Potent Multistage Antimalarial Drug. J. Infect. Dis. 2012, 205, 1278-1286, doi:10.1093/infdis/jis184.

31. Lindsay, D.S.; Butler, J.M.; Blagburn, B.L. Efficacy of Decoquinate against Neospora Caninum Tachyzoites in Cell Cultures. Vet. Parasitol. 1997, 68, 35-40, doi:10.1016/S0304-4017(96)01054-0.

32. Lindsay, D.S.; Nazir, M.M.; Maqbool, A.; Ellison, S.P.; Strobl, J.S. Efficacy of Decoquinate against Sarcocystis Neurona in Cell Cultures. Vet. Parasitol. 2013, 196, 21-23, doi:10.1016/j.vetpar.2013.02.008.

33. Lindsay, D.S.; Toivio-Kinnucan, M.A.; Blagburn, B.L. Decoquinate Induces Tissue Cyst Formation by the RH Strain of Toxoplasma Gondii. Vet. Parasitol. 1998, 77, 75-81, doi:10.1016/S0304-4017(98)00099-5. 
34. Li, Q.; Xie, L.; Caridha, D.; Zeng, Q.; Zhang, J.; Roncal, N.; Zhang, P.; Vuong, C.; Potter, B.; Sousa, J.; et al. Long-Term Prophylaxis and Pharmacokinetic Evaluation of Intramuscular Nano- and Microparticle Decoquinate in Mice Infected with P. Berghei Sporozoites. Malar. Res. Treat. 2017, 2017, 1-10, doi:10.1155/2017/7508291.

35. Lindsay, D.S.; Woods, K.M.; Upton, S.J.; Blagburn, B.L. Activity of Decoquinate against Cryptosporidium Parvum in Cell Cultures and Neonatal Mice. Vet. Parasitol. 2000, 89, 307-311, doi:10.1016/S0304-4017(00)00209-0.

36. Wang, H.; Li, Q.; Reyes, S.; Zhang, J.; Zeng, Q.; Zhang, P.; Xie, L.; Lee, P.J.; Roncal, N.; Melendez, V.; et al. Nanoparticle Formulations of Decoquinate Increase Antimalarial Efficacy against Liver Stage Plasmodium Infections in Mice. Nanomedicine Nanotechnol. Biol. Med. 2014, 10, 57-65, doi:10.1016/j.nano.2013.07.010.

37. van Gelder, M.M.H.J.; van Rooij, I.A.L.M.; Miller, R.K.; Zielhuis, G.A.; de Jong-van den Berg, L.T.W.; Roeleveld, N. Teratogenic Mechanisms of Medical Drugs. Hum. Reprod. Update 2010, 16, 378-394, doi:10.1093/humupd/dmp052.

38. Finnell, R.H. Teratology: General Considerations and Principles. J. Allergy Clin. Immunol. 1999, 103, S337-S342, doi:10.1016/S0091-6749(99)70259-9.

39. Pastor-Fernández, I.; Collantes-Fernández, E.; Jiménez-Pelayo, L.; Ortega-Mora, L.M.; Horcajo, P. Modeling the Ruminant Placenta-Pathogen Interactions in Apicomplexan Parasites: Current and Future Perspectives. Front. Vet. Sci. 2021, 7, 634458, doi:10.3389/fvets.2020.634458.

40. Müller, J.; Manser, V.; Hemphill, A. In Vitro Treatment of Besnoitia Besnoiti with the Naphto-Quinone Buparvaquone Results in Marked Inhibition of Tachyzoite Proliferation, Mitochondrial Alterations and Rapid Adaptation of Tachyzoites to Increased Drug Concentrations. Parasitology 2019, 146, 112-120, doi:10.1017/S0031182018000975.

41. Müller, J.; Aguado, A.; Laleu, B.; Balmer, V.; Ritler, D.; Hemphill, A. In Vitro Screening of the Open Source Pathogen Box Identifies Novel Compounds with Profound Activities against Neospora Caninum. Int. J. Parasitol. 2017, 47, 801-809, doi:10.1016/j.ijpara.2017.06.002.

42. Kropf, C.; Debache, K.; Rampa, C.; Barna, F.; Schorer, M.; Stephens, C.E.; Ismail, M.A.; Boykin, D.W.; Hemphill, A. The Adaptive Potential of a Survival Artist: Characterization of the in Vitro Interactions of Toxoplasma Gondii Tachyzoites with DiCationic Compounds in Human Fibroblast Cell Cultures. Parasitology 2012, 139, 208-220, doi:10.1017/S0031182011001776.

43. Sharifiyazdi, H.; Namazi, F.; Oryan, A.; Shahriari, R.; Razavi, M. Point Mutations in the Theileria Annulata Cytochrome $b$ Gene Is Associated with Buparvaquone Treatment Failure. Vet. Parasitol. 2012, 187, 431-435, doi:10.1016/j.vetpar.2012.01.016.

44. Sauvage, V.; Aubert, D.; Escotte-Binet, S.; Villena, I. The Role of ATP-Binding Cassette (ABC) Proteins in Protozoan Parasites. Mol. Biochem. Parasitol. 2009, 167, 81-94, doi:10.1016/j.molbiopara.2009.05.005.

45. Winzer, P.; Imhof, D.; Anghel, N.; Ritler, D.; Müller, J.; Boubaker, G.; Aguado-Martinez, A.; Ortega-Mora, L.-M.; Ojo, K.K.; VanVoorhis, W.C.; et al. The Impact of BKI-1294 Therapy in Mice Infected With the Apicomplexan Parasite Neospora Caninum and Re-Infected During Pregnancy. Front. Vet. Sci. 2020, 7, 587570, doi:10.3389/fvets.2020.587570.

46. Winzer, P.; Müller, J.; Aguado-Martínez, A.; Rahman, M.; Balmer, V.; Manser, V.; Ortega-Mora, L.M.; Ojo, K.K.; Fan, E.; Maly, D.J.; et al. In Vitro and In Vivo Effects of the Bumped Kinase Inhibitor 1294 in the Related Cyst-Forming Apicomplexans Toxoplasma Gondii and Neospora Caninum. Antimicrob. Agents Chemother. 2015, 59, 6361-6374, doi:10.1128/AAC.01236-15.

47. Anghel, N.; Imhof, D.; Winzer, P.; Balmer, V.; Ramseier, J.; Haenggeli, K.; Choi, R.; Hulverson, M.A.; Whitman, G.R.; Arnold, S.L.M.; et al. Endochin-like Quinolones (ELQs) and Bumped Kinase Inhibitors (BKIs): Synergistic and Additive Effects of Combined Treatments against Neospora Caninum Infection in Vitro and in Vivo. Int. J. Parasitol. Drugs Drug Resist. 2021, 17, 92106, doi:10.1016/j.ijpddr.2021.08.007.

48. Fernández-Escobar, M.; Calero-Bernal, R.; Regidor-Cerrillo, J.; Vallejo, R.; Benavides, J.; Collantes-Fernández, E.; OrtegaMora, L.M. Isolation, Genotyping, and Mouse Virulence Characterization of Toxoplasma Gondii From Free Ranging Iberian Pigs. Front. Vet. Sci. 2020, 7, 11, doi:10.3389/fvets.2020.604782.

49. Sánchez-Sánchez, R.; Ferre, I.; Regidor-Cerrillo, J.; Gutiérrez-Expósito, D.; Ferrer, L.M.; Arteche-Villasol, N.; Moreno-Gonzalo, J.; Müller, J.; Aguado-Martínez, A.; Pérez, V.; et al. Virulence in Mice of a Toxoplasma Gondii Type II Isolate Does Not 
Correlate With the Outcome of Experimental Infection in Pregnant Sheep. Front. Cell. Infect. Microbiol. 2019, 8, 436, doi:10.3389/fcimb.2018.00436.

50. Imhof, D.; Anghel, N.; Winzer, P.; Balmer, V.; Ramseier, J.; Hänggeli, K.; Choi, R.; Hulverson, M.A.; Whitman, G.R.; Arnold, S.L.M.; et al. In Vitro Activity, Safety and in Vivo Efficacy of the Novel Bumped Kinase Inhibitor BKI-1748 in Non-Pregnant and Pregnant Mice Experimentally Infected with Neospora Caninum Tachyzoites and Toxoplasma Gondii Oocysts. Int. J. Parasitol. Drugs Drug Resist. 2021, 16, 90-101, doi:10.1016/j.ijpddr.2021.05.001.

51. Winzer, P.; Anghel, N.; Imhof, D.; Balmer, V.; Ortega-Mora, L.-M.; Ojo, K.K.; Van Voorhis, W.C.; Müller, J.; Hemphill, A. Neospora Caninum: Structure and Fate of Multinucleated Complexes Induced by the Bumped Kinase Inhibitor BKI-1294. Pathogens 2020, 9, 382, doi:10.3390/pathogens9050382.

52. Costa, J.-M.; Pautas, C.; Ernault, P.; Foulet, F.; Cordonnier, C.; Bretagne, S. Real-Time PCR for Diagnosis and Follow-Up of Toxoplasma Reactivation after Allogeneic Stem Cell Transplantation Using Fluorescence Resonance Energy Transfer Hybridization Probes. J. Clin. Microbiol. 2000, 38, 2929-2932, doi:10.1128/JCM.38.8.2929-2932.2000.

53. Müller, J.; Aguado-Martínez, A.; Ortega-Mora, L.-M.; Moreno-Gonzalo, J.; Ferre, I.; Hulverson, M.A.; Choi, R.; McCloskey, M.C.; Barrett, L.K.; Maly, D.J.; et al. Development of a Murine Vertical Transmission Model for Toxoplasma Gondii Oocyst Infection and Studies on the Efficacy of Bumped Kinase Inhibitor (BKI)-1294 and the Naphthoquinone Buparvaquone against Congenital Toxoplasmosis. J. Antimicrob. Chemother. 2017, 72, 2334-2341, doi:10.1093/jac/dkx134. 